\title{
Recycling Concrete: An Undiscovered Source of Ultrafine Particles
}

\author{
Prashant Kumar $^{\mathrm{a}, \mathrm{b},{ }^{*}, \text { Lidia Morawska }}{ }^{\mathrm{c}}$ \\ ${ }^{a}$ Department of Civil and Environmental Engineering, Faculty of Engineering and Physical \\ Sciences (FEPS), University of Surrey, Guildford GU2 7XH, United Kingdom \\ ${ }^{b}$ Environmental Flow (EnFlo) Research Centre, FEPS, University of Surrey, Guildford GU2 \\ $7 X H$, United Kingdom \\ ${ }^{\mathrm{c}}$ International Laboratory for Air Quality and Health, Queensland University of Technology, \\ GPO Box 2434, Brisbane QLD, 4001, Australia
}

\section{GRAPHICAL ABSTRACT}

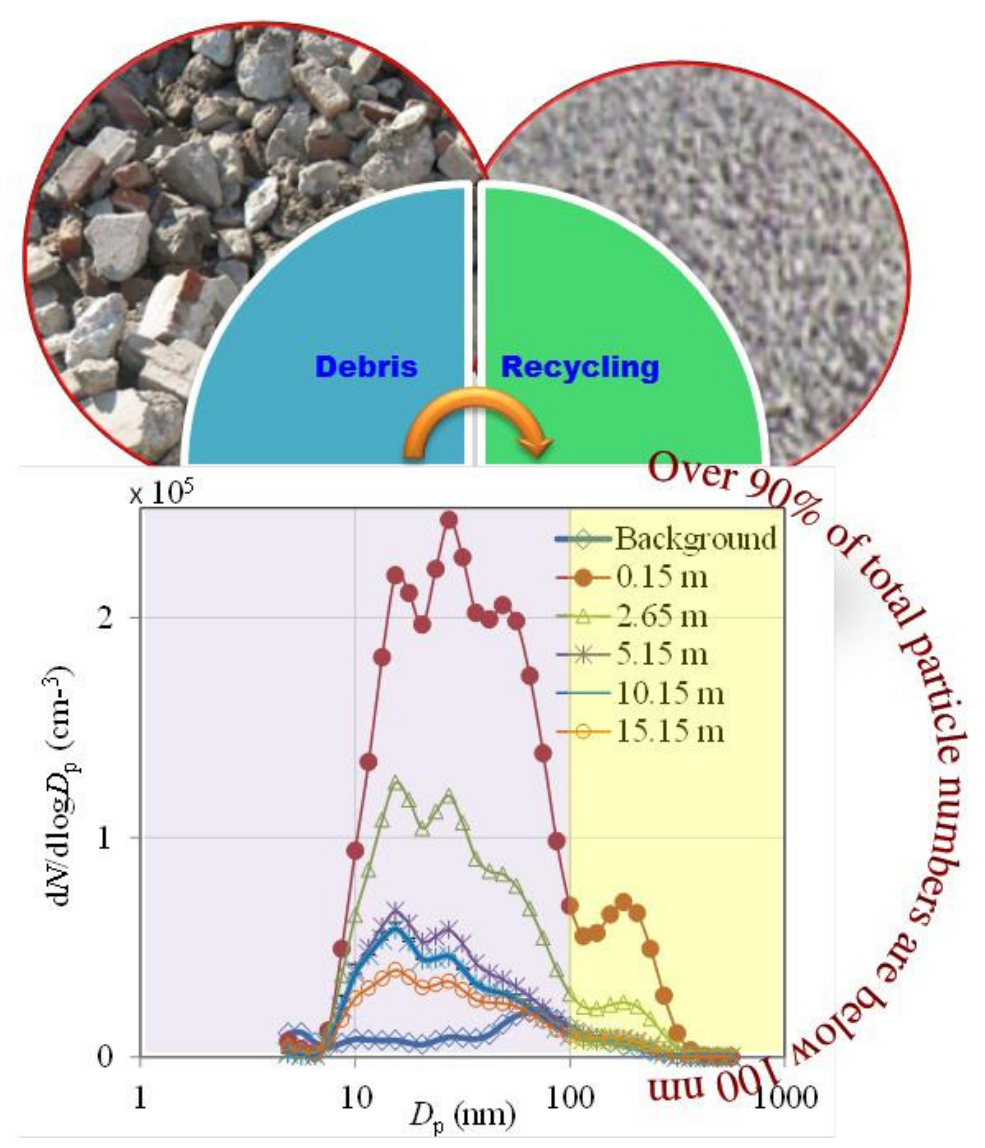

"Corresponding author: Tel. +44 1483 682762; fax: +44 1483 682135; Email addresses:

P.Kumar@surrey.ac.uk, Prashant.Kumar@cantab.net 


\begin{abstract}
While concrete recycling is practiced worldwide, there are many unanswered questions in relation to ultrafine particle (UFP; $D_{\mathrm{p}}<100 \mathrm{~nm}$ ) emissions and exposure around recycling sites. In particular: (i) Does recycling produce UFPs and in what quantities? (ii) How do they disperse around the source? (iii) What impact does recycling have on ambient particle number concentrations (PNCs) and exposure? (iv) How effective are commonly used dust respirators to limit exposure? We measured sizeresolved particles in the 5-560 $\mathrm{nm}$ range at five distances between 0.15 and $15.15 \mathrm{~m}$ that were generated by an experimentally simulated concrete recycling source and found that: (i) the size distributions were multimodal, with up to $~ 93 \%$ of total PNC in the UFP size range; and (ii) dilution was a key particle transformation mechanism. UFPs showed a much slower decay rate, requiring $\sim 62 \%$ more distance to reach $10 \%$ of their initial concentration compared with their larger counterparts in the 100-560 nm size range. Compared with typical urban exposure during car journeys, exposure decay profiles showed up to $\sim 5$ times higher respiratory deposition within $10 \mathrm{~m}$ of the source. Dust respirators were found to remove half of total PNC; however the removal factor for UFPs was only $57 \%$ of that observed in the 100-560 $\mathrm{nm}$ size range. These findings highlight a need for developing an understanding of the nature of the particles as well as for better control measures to limit UFP exposure.
\end{abstract}

Keywords: Ultrafine particles; Construction and demolition; Concrete waste recycling; Particle size distribution; Particle number exposure; Particle exposure mask

\section{INTRODUCTION}

The current world population of over 7 billion people is expected to reach $\sim 8.3$ billion by 2030 . The development of urban infrastructure is an inevitable consequence of this growth and implies the need for both construction and demolition (C\&D) activities. For instance, about 30 billion tonnes of concrete were consumed globally in 2006 compared with 2 billion tonnes in 1950; about $20-80 \%$ of which could be C\&D waste, depending on construction traditions in different countries (WBCSD, 2009). As a consequence, nearly 317 Mt of concrete waste is generated annually in the United States compared with $~ 510 \mathrm{Mt}$ in Europe (WBCSD, 2009). In China, the annual production of waste concrete accounts for about $1 / 3$ of the total $\mathrm{C} \& \mathrm{D}$ waste $(\mathrm{Li}, 2008)$, and a forecast annual increase of $8 \%$ suggests that the 239 Mt of waste concrete production in 2010 will increase to $\sim 638 \mathrm{Mt}$ in 2020 (Shi and $\mathrm{Xu}, 2006)$. Pressure to preserve Earth's rapidly depleting natural resources makes the recycling of concrete a thriving business, as it is deemed an environmental friendly process. The Waste Framework Directive 2008/98/EC requires member states of European Union to take any necessary measures to recycle a minimum of $70 \%$ C\&D waste (by weight) by 2020 (Monier et al., 2011). However, recycling of concrete may also produce particulate matter in various size ranges (Kumar et al., 2012a, b). Coarse $\left(\mathrm{PM}_{10} ; \leq 10 \mu \mathrm{m}\right)$ and fine $\left(\mathrm{PM}_{2.5} ; \leq 2.5 \mu \mathrm{m}\right)$ particulate matter emissions from recycling activities have not often been quantified and ultrafine particle (UFP; $<100 \mathrm{~nm}$ ) emissions - which are the 
focus of this study - have received even less attention.

Fresh concrete is produced by mixing the cement, aggregates, admixtures and water, and particle emissions during the handling of these ingredients and their mixing may occur (Raki et al., 2010; Holman et al., 2014). Also, particles in different size ranges are usually created at various stages of $\mathrm{C} \& \mathrm{D}$, including the demolition of structures and the creation of aggregate after mining, crushing and grading (Kumar et al., 2012b). Assessment of such emissions is however beyond the scope of this work, which is limited to recycling activities. The recycling of concrete is carried out by movable, portable or stationary plants, and all types of plants operate based on the same recycling principle. The process involves primary and secondary crushers to break larger-sized concrete debris into smaller-sized aggregate, and these crushers usually have perforated openings to allow particles to escape into the ambient environment. The crushed debris are then passed through the screeners to size segregate the aggregates into the desired size ranges ( $\mathrm{Li}, 2008$ ). Throughout all of these stages, the concrete debris, which contains nano-sized pores (Raki et al., 2010), gets fractured and undergoes mechanical attrition, thus releasing particles into the ambient environment in a similar manner to what which was simulated in our experiments (see Section 2). Numerous types of nanoadditives (e.g. nano-silica, $\mathrm{Fe}_{2} \mathrm{O}_{3}, \mathrm{SiO}_{2}$ and $\mathrm{TiO}_{2}$ ) and nanocomposites are added as admixtures to the concrete mix for enhancing workability and strength (Sanchez and Sobolev, 2010). Despite the relatively high cost of these nano-enabled additives, their use in concrete is likely to increase in the future, due to their valuable properties (Sanchez and Sobolev, 2010). As a result, during the demolition and recycling of concrete, these additives could potentially generate particles in the UFP size range (Kumar et al., 2012a).
Exposure to concrete recycling particles poses risk to the workers at the recycling sites, as well as the communities residing nearby. The UFPs produced from the C\&D activities are likely to have much lower volatile fraction than those generated by vehicle exhaust (Charron and Harrison, 2003; Dall'Osto et al., 2011; Kumar et al., 2010b; Morawska et al., 2008) or nonvehicle exhaust sources (Kumar et al., 2013b) such as ships (Jonsson et al., 2011), aircrafts (Schröder et al., 1998) and biomass burning (Janhall et al., 2010). Hence a relatively longer atmospheric life time of $C \& D$ produced UFPs is expected, allowing them to travel for longer distances and resulting in both the occupational exposure to 'on-site workers and personal exposure to the 'passers-by' and 'occupants of nearby buildings' (Kumar et al., 2012b). Our understanding of such exposure (i.e. that which is attributed to C\&D activities) is currently lacking and the scientific community has only just started to recognise this previously ignored aspect of UFP exposure science (Kumar et al., $2012 b$ ). Furthermore, detailed information about the possible UFP-specific health and safety risks is generally lacking and consequently, there are currently no regulatory guidelines for limiting exposure to UFPs. In Europe, a general framework is provided by regulations relating to the occupational safety and health of workers (EU Directive 89/391/EEC; Directive 98/24/EC), as well as under the REACH (Registration, Evaluation, Authorization and Restriction of Chemicals) guidelines for risk assessments, which relate to the synthesis, handling and transport of nanomaterials in workplaces. However, specific guidelines relevant to UFPs arising from $C \& D$ activities are non-existent and this lack of information makes it challenging to conduct proper risk assessments and provide for a safe and healthy workplace (Kuhlbusch et al., 2011). Current hypotheses suggest that exposure to UFPs may have greater potential to pose risk to human health compared with their larger counterparts (WHO, 2013), although the conformity is yet to appear from the 
long-term exposure studies that are currently unavailable (HEI, 2013). Given their potential health risks (Heal et al., 2012), developing an understanding of UFP release from $C \& D$ activities is important. The lack of studies on this topic also calls for further studies to provide C\&D industries new mitigation strategies, methods and tools to appropriately manage these emerging risks.

To date, extremely limited information exists on this topic as highlighted in review by Kumar et al. (2013b). This work is the continuation of an effort to understand the emission characteristics of UFPs from various building activities and focuses on the recycling of concrete debris in a simulated environment. The aims of this work are to understand the emission strength, size distribution, dispersion behaviour and decay profile of particle number concentrations (PNCs), together with their associated exposure, as well as the effectiveness of commonly used dust respirators.

\section{MATERIALS AND METHODS 2.1 Sampling set up and data collection}

The recycling process is conducted by processing concrete debris to produce recycled concrete aggregate. Five different $30 \mathrm{~kg}$ samples were prepared, each with similar constituents and particles ranging in size from 5-20 mm. The samples comprised of conventional Portland cement concrete debris, which had been brought from a nearby waste recycling site that accommodates concrete waste from several C\&D sites. This mixture of products is representative of real life recycling activities, where different types of concrete are put into the crusher and sorted into different sized aggregate. To simulate this process, the combined 'dry' material was placed into a standard "electricity operated" rotating drum mixer (manufacturer: ELE International; model: EL34-3540/01), which has $\sim 1.20 \mathrm{~m}$ height and was operated at a speed of $\sim 60 \mathrm{rpm}$ by a $1.5 \mathrm{~kW}$ electric motor and we monitored the number of 5-
$560 \mathrm{~nm}$ particles produced at different sampling locations inside a controlled indoor environment. The primary reason for designing our experiments in a controlled environment was to capture the real emissions of UFPs from the concrete recycling itself. Should the study be carried out around an operational recycling plant, a number of practical and technical constraints would have complicated the experiments and defeated the purpose of our study. For example, it is highly challenging to make emission measurements at, or very close, to the source, due to health and safety issues. More importantly, an operational site environment is likely to be contaminated by emissions from other sources (e.g. site machinery, varying background), making it difficult to disentangle real emissions of the UFPs from this activity from the total emissions measured. The samples used did not include any commercial additives and therefore, the influence of concrete admixtures on the release of UFPs is not examined here.

Since the aim of this work included the emission of new UFPs and their subsequent decay as they move away from the source, five sampling locations at five different radial distances, each $\sim 1.2 \mathrm{~m}$ above ground level, were chosen as seen in Supplementary Information, SI, Figure S1. The closest sampling location was $0.15 \mathrm{~m}$ from the source (referred to hereafter as $L_{1}$ ), located above the perforated lid of the mixer, followed by distances of $2.65 \mathrm{~m}\left(L_{2}\right)$, $5.15 \mathrm{~m}\left(L_{3}\right), 10.15\left(L_{4}\right)$ and $15.15 \mathrm{~m}\left(L_{5}\right)$ (see SI Figure S1). Measurements at each of the five sampling locations were repeated twice, once with a 'fresh' sample and once with a sample that was 'used' in the previous set of measurements (see Table 1). This method was chosen to ensure that each sample was used identically prior to the measurement and that the emission strength of each sample was the same. Each measurement was taken for 10 minutes during the recycling process, followed by 
Table 1. Summary of sampling locations and measurements matrix. The word " $S$ " represents the sample name; first and second characters of the subscripts indicate the sample number and the number of times a sample is used, respectively. $S_{1}-S_{5}$ were fresh samples that were used during the $1^{\text {st }}$ set of samples and the same samples were used in the $2^{\text {nd }}$ set of measurements after their use in preceding set for maintaining the same emission strength during each set of measurements. sampling flow rate of $6.5 \mathrm{~L} \mathrm{~min}^{-1}$ and can take measurements in 32 size bins with a sampling frequency of up to $10 \mathrm{~Hz}$ and a time response $\left(\mathrm{T}_{10-90 \%}\right)$ equal to $500 \mathrm{~ms}$, without an inlet tube. In this study, we used a $0.25 \mathrm{~m}$ long, thermally conductive silicon sampling tube, with an internal diameter of $0.55 \mathrm{~cm}$, and given to its short length, particle loss due to diffusion within the sampling tube was considered negligible (Kumar et al., 2008c). A detailed description of the working principles and the application of the DMS50 for ambient measurements can be found in a review by Kumar et al. (2010b).

A LaCrosse WS-2350 weather station was used to measure the average ambient temperature and relative humidity over the measurement periods in the laboratory that were found to be $19.5 \pm 1.5^{\circ} \mathrm{C}$ and $59 \pm 4 \%$, respectively. In addition, a standard rotating drum mixer, with both fixed and floating arms, was used to simulate the recycling of samples (see Section 2.1).

\subsection{Estimation of exposure doses}

Exposure of workers to UFPs can have detrimental health effects. Respiratory deposition strongly depends on particle size, therefore number-based deposition doses for UFPs are generally much higher compared with larger sized particles (ICRP, 1994). Knowledge of size-resolved PNDs is essential for accurately estimating the deposition doses in the respiratory region (i.e. sum of alveolar, tracheobronchial and extrathoracis regions), which can occur as a result of exposure to airborne particles during recycling events (Kumar et al., 2012c). Average size-resolved PNDs measured at each sampling location were used, together with size-resolved deposited efficiency, as proposed by the ICRP model (ICRP, 1994). The estimates were made based on the condition of light exercise, with the volume of inhaled air by an adult man given as $1.5 \mathrm{~m}^{3} \mathrm{~h}^{-1}$ (Hinds, 1999).

our previous fast response measurements (Carpentieri and Kumar, 2011; Joodatnia et al., 2013a, b). The instrument uses a 


\subsection{Dust respirator test}

In order to test the effectiveness of commonly used dust respirators (i.e. masks), we selected masks that were used during construction work and met the EU specifications, as used in the construction industry (PPE directive EN149:2001 and the Medical directive EN14683:2005). All the masks used for experiments were having the above-noted classification and were made by the same manufacturer (GRANDE CFB3S-P1; EN149:2001+A1:2009). To affix the mask to the DMS50, we designed a small cubical shape plywood box, which was open at one end, where the mask was fastened, in order to draw the sample through it (see SI Figure $\mathrm{S} 2)$. A hole, equal to the external diameter of sampling tube $(\sim 0.95 \mathrm{~cm})$, was made in the box wall on the opposite side of the mask, to insert the inlet of the sampling tube, which was used to record the amount of particles travelling through the mask. The experiments were repeated with and without the mask, in order to determine the number of particles filtered out by the dust respirator.

\section{RESULTS AND DISCUSSION}

\subsection{PNDs at and away from the source}

Figure 1 shows the average PNDs

during background measurements (no activity period), as well as for all five sampling locations during recycling activities (activity period). It can be seen that the PND's measured at locations $L_{1-5}$ were significantly higher than background levels (e.g. peak average PNDs at $\sim 27 \mathrm{~nm}$ being $2.45 \times 10^{5} \mathrm{~cm}^{-3}$ at $L_{1}$ compared with the background values of $9.23 \times 10^{3} \mathrm{~cm}^{-3}$; Figure 1), which clearly indicates the release of particles during the concrete recycling process. The majority of this increase was seen in the UFP size range and such a large increase was not seen for particles over $100 \mathrm{~nm}$ in diameter. As expected, the most pronounced PNDs were observed close to the source at $L_{1}$. The PNDs were multimodal, showing peak diameters at $\sim 15,27,56$ and $154 \mathrm{~nm}$, and the magnitude of the PNDs decreased with increasing distance from the source (Figure 1). The PND spectrum maintained its multimodal nature at all of the sampling locations and moved up or down without appreciable changes in peak diameters. This negligible change in both the peak diameters and shape of the PNDs at all the five sampling points indicates the dominance of dilution over other transformation processes (Kumar et al., 2008b).

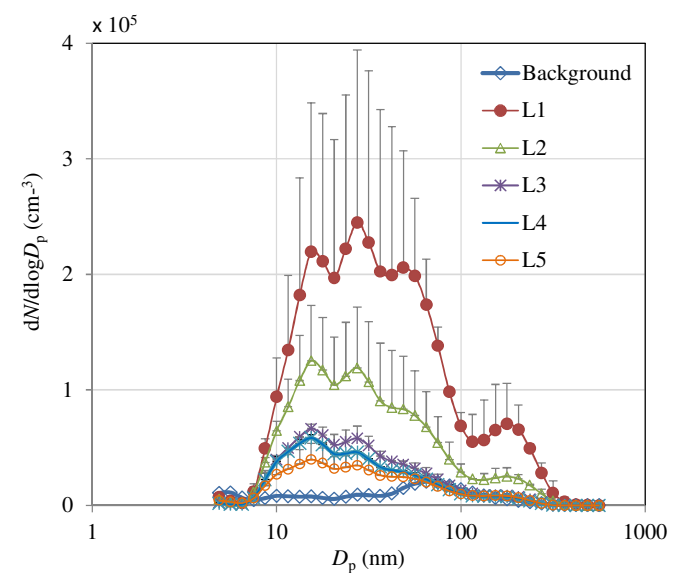

Figure 1. Average PNDs during the background and recycling process. The error bars indicate the standard deviation values obtained during the sets 1 and 2 of experiments.

Mechanical re-suspension and attrition between the concrete particles during recycling were major physical processes, but these do not clearly explain the potential formation mechanisms that caused the various PND modes within the UFP size range. Furthermore, the nucleation mode (those below $\sim 30 \mathrm{~nm}$ ) particles are generally formed through the gas-to-particle conversion (Dall'Osto et al., 2011; Kulmala et al., 2013), however there were no such precursor gases available to trigger this process during the recycling activity. It can be argued that the motor (Morawska et al., 2009) of the mixer itself produced these particles, but a separate measurement campaign carried out to identify mixer's emissions showed modest contributions towards the total particle numbers in this size range (see SI Figure S3 and Table S1). Therefore, the presence of nucleation mode 
particles in appreciable quantities was surprising. Further studies focusing on detailed chemical characterization are needed to accurately understand the exact formation mechanism of these nano-sized particles.

\subsection{PNCs in various size ranges at and away from the source}

Figure 2a shows the background and total PNCs close to and away from the source at all the sampling locations $\left(L_{1}-L_{5}\right)$ during the concrete recycling process. As expected, the largest PNCs were noted close to the source at $L_{1}\left(2.18 \pm 0.85 \times 10^{5}\right.$ $\mathrm{cm}^{-3}$ ), against a steady background of $0.17 \times 10^{5} \mathrm{~cm}^{-3}$, resulting in a rise of over 17-times the background values. The concentrations measured in this study were found to be in agreement with our previous findings (Kumar et al., 2012c) where the total PNCs during the dry recycling process were found to be $\sim 2.51 \times 10^{5} \mathrm{~cm}^{-3}$. The total PNCs at $L_{2}, L_{3}, L_{4}$ and $L_{5}$ were found to decrease by $\sim 2.1,4.3,5.1$ and 6.5 times over the $L_{1}$ levels, respectively (Figure 2a). There was over a 2-fold decrease in PNC between the first two $\left(L_{1}\right.$ and $\left.L_{2}\right)$ and second two $\left(L_{2}\right.$ and $\left.L_{3}\right)$ sampling locations, but this decrease was modest $(\sim 30 \%)$ between $L_{4}$ and $L_{5}$. The sharp decay of PNC close to the source was expected, due to much larger concentration gradients between the emission and background levels, as was also reported by a number of vehicle emission studies (Carpentieri and Kumar, 2011; Fujitani et al., 2012; Pirjola et al., 2006; Zhu et al., 2002).

Further inspection of the data revealed that the proportion of UFPs during the background measurements was $~ 82 \%$ of the total PNCs, which increased between $~ 88 \%$ and $\sim 93 \%$ at the sampling locations (see Figure 2b). This increase in UFPs came at the expense of particles in the 100-300 nm range, which decreased from a background level of $\sim 17 \%$ to $\sim 7-12 \%$ at the sampling locations. A relatively smaller fraction of the PNCs in the UFP size range at $L_{1}$, compared with $L_{2}-L_{5}$, can be explained by the fact that the average PNCs in both the
5-100 $\mathrm{nm}$ and 100-560 $\mathrm{nm}$ size range at $L_{1}$ are up to $\sim 4$-times higher than those at $L_{2}-L_{5}$ (Figure 2a) - this is expected due to the close proximity of $L_{1}(0.15 \mathrm{~m})$ from the source. The higher proportion of the preexisting, larger-sized (100-560 nm), particles provides relatively larger surface area, compared to what is available at $L_{2}-L_{5}$, for the smaller-sized nucleation mode particles to deposit onto their surfaces, and resulting into a relatively smaller fraction $(\sim 88 \%)$ at $L_{1}$ compared with $\sim 90-93 \%$ at $L_{2}-L_{5}$. In addition, PNCs in the UFP size range dominated total PNCs, irrespective of sampling location.

Using the methodology described in SI Section S1, emission rates were computed based on the PNC measured at $L_{1}$ and were found to be $1.71 \pm 1.03 \times 10^{7} \mathrm{~s}^{-1}$, or $5.71 \pm 3.44 \times 10^{5} \quad \mathrm{~s}^{-1} \quad \mathrm{~kg}^{-1}$ of concrete recycled. Multiplying the mass-based emission rates with the typical recycling time taken by a unit mass of concrete at operational recycling plants, which varies from a few seconds to 10's of seconds depending on the capacity of an individual plant, can produce generalised emission rates in the form of $\# \mathrm{~kg}^{-1}$ (i.e. number of particles released by a unit mass of concrete debris recycled). While time based emission rates $\left(\# \mathrm{~s}^{-1}\right)$ are useful for dispersion modelling, the mass based emission rates (\# $\mathrm{kg}^{-1}$ ) can be instrumental for compiling local emission inventories for recycled concrete. For instance, during past years in the European Union (EU), C\&D waste production was found to have a linearly increasing trend with time (with $\mathrm{R}^{2}=0.96$ ), increasing from a level of 1.1 tons per person per year in 2002, to 1.8 and 2.0 in 2004 and 2006, respectively (Monier et al., 2011). Extrapolating these figures to 2010, for which particle number emissions from a dominant source (road vehicles) of UFPs in 28 EU countries (EU28) are available for comparison purposes (Paasonen et al., 2013), provides approximately $\sim 2.8$ tons 


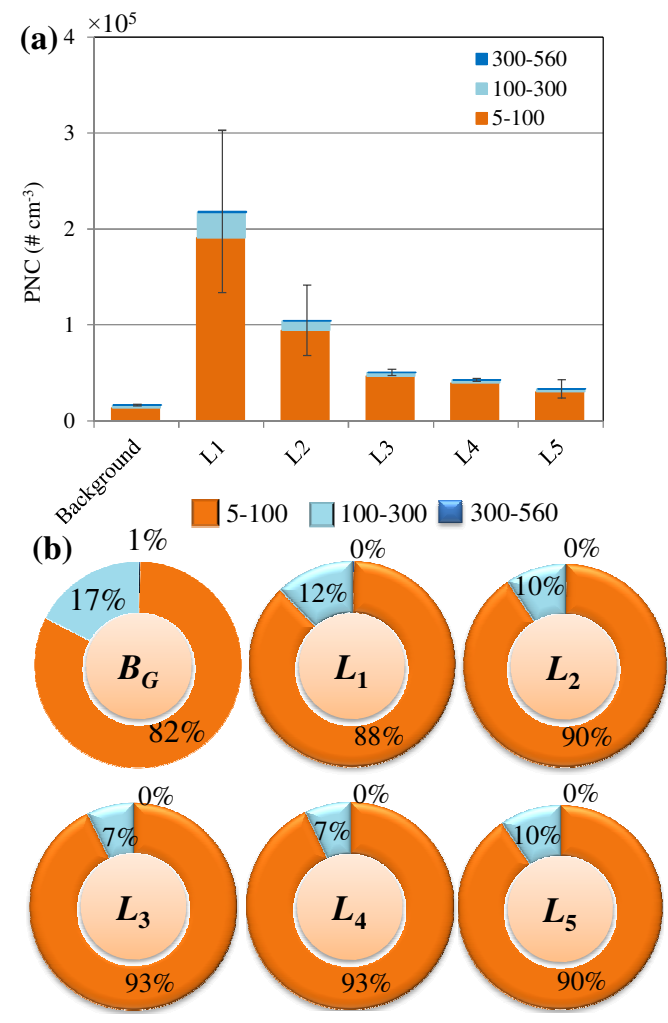

Figure 2. Average (a) PNCs, and (b) fraction of PNCs in various size ranges during the background measurements and at all the five sampling locations.

per person per year $C \& D$ waste produced in 2010. About $40 \%$ of this C\&D waste is recycled annually (Monier et al., 2011). Multiplying the total recycled concrete with the total population $\left(\sim 5.06 \times 10^{8}\right)$ during 2010 in EU28 (UNECE, 2013), as well as the emission factors obtained above and the typical recycling duration between the entry of concrete debris and exit of recycled concrete from the plant as $\sim 100 \mathrm{~s}$ during which particle emissions are likely to escape to the ambient environment, gives annual particle number emissions from concrete recycling as $\sim 3.24 \times 10^{19}$. These estimates are indeed indicative, based on broad assumptions, showing a modest fraction compared with the total particle number emissions from road traffic in EU28 $\left(\sim 9.45 \times 10^{26}\right)$ (Paasonen et al., 2013; Kumar et al., 2014), Brisbane, Australia $\left(1.08 \times 10^{25}\right)($ Keogh et al., 2009) or Delhi, India $\left(1.37 \times 10^{25}\right)$ (Kumar et al., 2011a). Currently these insignificant recycling emissions of particle numbers may become apparent in future due to declining particle number emissions from vehicle exhausts in Europe as a result of renewable (Kumar et al., 2010a) and low sulphur fuels (Jones et al., 2012) and significant improvements in engine technology and exhaust aftertreatment systems brought by the stringent exhaust emission standards (EU, 2008). Furthermore, these localised emissions may prove important from the occupational exposure perspective given that the PNC close to the recycling sites could be up to an order of magnitude higher than those generally found at urban roadsides (see details in Section 3.4).

\subsection{PNC decay profiles}

PNC decay profiles can be used to estimate concentrations and exposure at different receptor points. Figure 3 shows the normalised PNC profiles, which represent the ratio of PNCs at a sampling point against the largest concentrations (i.e. close to the source at $L_{1}$ ). The data in the various size ranges (i.e. 5-100, 100-300 or $5-560 \mathrm{~nm}$ ) fit well to a logarithmic decay profile, giving a $\mathrm{R}^{2}$ value between 0.95 and 0.98 . Note that particles in the $300-560 \mathrm{~nm}$ range are not plotted due to their negligible concentrations, by number, compared with other size ranges (see Figure $2 b$ ).

Particles in all size ranges showed identical decay profiles (Figure 3). Their slope varied between 0.19 (for 5-100 nm) and 0.20 (for $100-300$ or $5-560 \mathrm{~nm}$ ), despite the fact that the extent of dilution was nearly the same at all sampling locations, due to the similar level of turbulence generated by the ambient conditions and the negligible movement of people in the sampling space. The lower value of the slope for particles in the $5-100 \mathrm{~nm}$ size range is indicative of their slower rate of decay compared with the other two size ranges. This observation is in line with our previous findings, where it was noted that particles in the UFP size range, in an ambient environment, do not necessarily behave in the same manner as their larger counterparts, under identical dilution conditions (Kumar et al., 2008a). 
For example, UFP concentration reached its $50 \%$ - and $10 \%$-values at $\sim 2.2$ and $17 \mathrm{~m}$, respectively, compared with $\sim 1.8$ and 10.5 $\mathrm{m}$ for particles in the $100-300 \mathrm{~nm}$ size range (see Figure 3). This decay trend for UFPs is concerning, particularly from an exposure point of view, because UFPs are much more likely to deposit in the respiratory regions of the lung compared with larger sized particles (ICRP, 1994).

The dispersion of particles and any resulting exposure at a receptor location is expected to depend on the stability of atmospheric conditions, emission strength and the height of the source (Holmes and Morawska, 2006; Vardoulakis et al., 2003). In relation to the latter, the concentration profiles observed in Figure 3 are presented in non-dimensional form (i.e. $z / L$ ) by dividing the source height $(z=1.20 \mathrm{~m})$ by the distance $(L)$ of each sampling location. The total PNCs reached $50 \%$ and $10 \%$ of their initial concentrations at $z / L=0.63$ (1.9 $\mathrm{m})$ and $0.10(11.9 \mathrm{~m})$, respectively. The meteorological conditions observed during the measurements represent "slightly stable" atmospheric conditions at real operational sites. This means that if "neutral" and "unstable" atmospheric conditions prevail, which occur $\sim 80 \%$ of the time in the UK, a relatively greater dispersion of released emissions can be expected. This dispersion would of course be offset by the much higher particle emissions from an operational recycling plant.

\subsection{Exposure assessment}

Figure 4 shows the normalised value of respiratory deposition doses for different size ranges at the chosen sampling locations. The decay profile of deposition mimics the trend of concentration decay profile as seen in Figure 3, and shows similar logarithmic decay, with a reasonably good $\mathrm{R}^{2}$ value between 0.96 (for $100-300 \mathrm{~nm}$ ) and 0.98 (for 5-100 and 5-560 $\mathrm{nm})$. Due to a larger proportion of PNCs

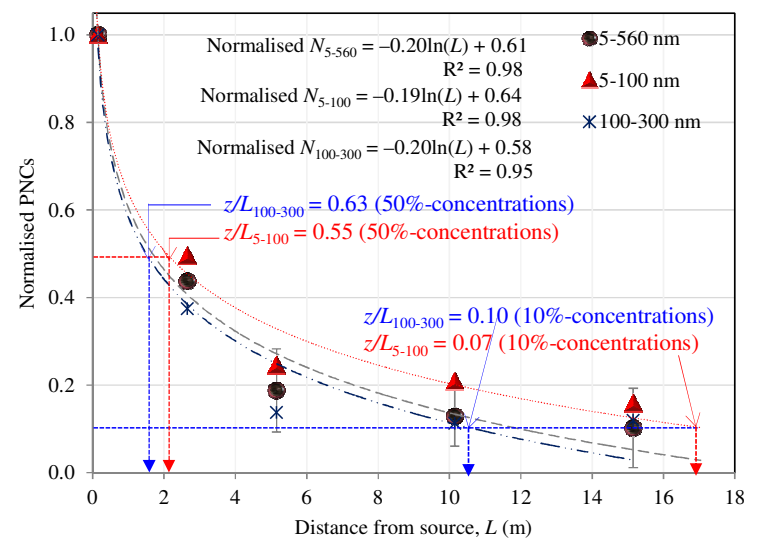

Figure 3. Decay profile of PNCs in various size ranges. The y-axis represents the normalised PNCs at each sampling distance $(L)$ against the highest concentrations at $L_{1} ; z(=1.2 \mathrm{~m})$ is the sampling height. The arrows marked on x-axis reflect the distance from the source in meters and the values of the decay slopes for different size ranges are seen in equations of various decay profiles. Error bars represent the standard deviation of PNCs in the 5-560nm range over both sets of measurements. Standard deviation bars for PNCs in the 5-100nm and $100-300 \mathrm{~nm}$ range are not plotted for the sake of clarity.

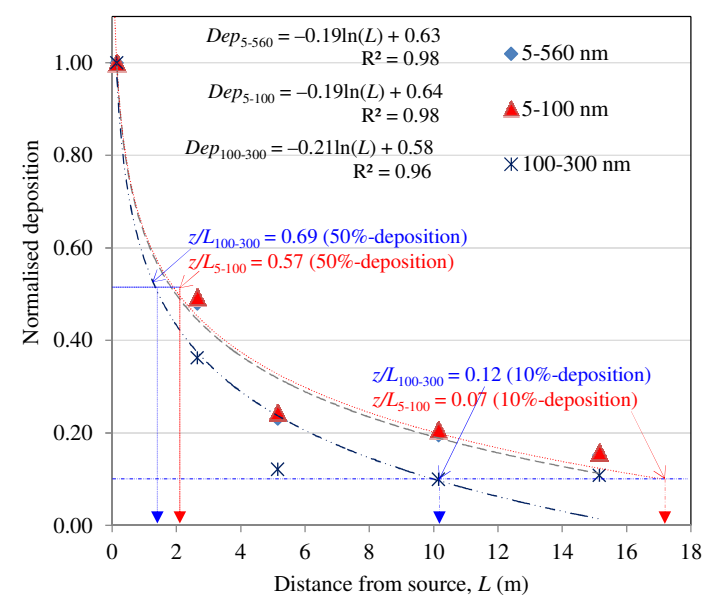

Figure 4. Decay profiles of respiratory deposition rates in various size ranges. The yaxis represents the normalised deposition at each sampling distance $(L)$ against the highest doses $\left(1.49 \times 10^{11} \mathrm{~h}^{-1}\right)$ at $L_{l}$. 
being in the UFP size range, the decay profile, as well as the 50\%- and $10 \%$ concentration decay distances for 5-100 nm particle deposition doses were identical to those observed for PNC decay (Figure 3). This finding was expected given that the deposition doses changed proportionally with PNC values.

In absolute terms, the deposited fraction of total PNCs were found to be 14.9, 7.16, $3.45,2.92$ and $2.27\left(\times 10^{10}\right) \mathrm{h}^{-1}$ during exposure at $L_{1}, \quad L_{2}, \quad L_{3}, \quad L_{4}$ and $L_{5}$, respectively (Figure 4). Since there are no similar data available to conduct a direct comparison, we compared our deposition estimates with respiratory deposition due to exposure in transport microenvironments (e.g. car cabins) and urban roadsides. For instance, Joodatnia et al. (2013a) estimated the deposition of particles in the range $3.30 \pm 3.05 \times 10^{10} \mathrm{~h}^{-1}$ during car journeys in a typical UK town, Guildford. Based on the average PNC data measured at 24 different roadside locations within 13 different European cities, average respiratory deposition was estimated as $3.61 \pm 0.17$ $\times 10^{10} \mathrm{~h}^{-1}$ (Kumar et al., 2013a). These were found to be identical to the estimated deposition at $\sim 10 \mathrm{~m}\left(L_{4}\right)$, but lower than those observed at $L_{1}$ and $L_{2}$. Another interpretation of these results could be that the exposure levels within $10 \mathrm{~m}$ of the source were likely to be much higher than during a typical car journey or at urban roadsides, which would go down logarithmically at further distances. The above estimates are representative of a small-scale recycling activity. The PNCs and related exposure at larger capacity recycling plants are expected to increase in proportion to the emission rates, which can be approximated by multiplying our emission factors (\# $\mathrm{kg}^{-1} \mathrm{~s}^{-1}$; Section 3.2) with the recycling capacity of a plant (see SI Section S1).

\subsection{Effectiveness of control measures (dust respirators)}

As seen in SI Figure S4, PNC began to drop almost immediately, as soon

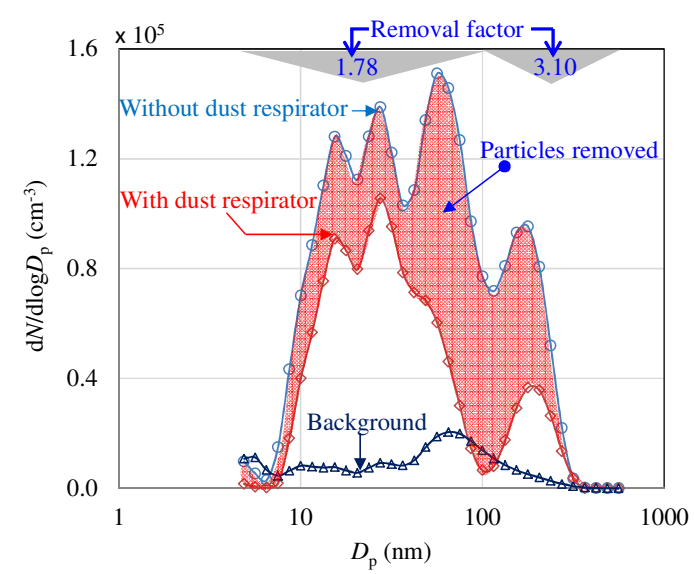

Figure 5. PNDs with and without the dust respirator; shaded area shows the particles removed by the dust respirator. Removal factor is the ratio of PNCs in a given particle size range before and after using the mask.

as the dust respirator was applied, due to the filtering of particles through the mask. PNC then increased immediately back up to their previous levels as soon as the dust respirator was removed. Figure 5 shows the average PNDs with $\left(8.04 \times 10^{4} \mathrm{~cm}^{-3}\right)$ and without $\left(1.58 \times 10^{5} \mathrm{~cm}^{-3}\right)$ the dust respirator, from which a clear reduction in total average PNC can be seen after affixing the respirator. The respirators used had a protection factor of 4, based on their classification in EN149:2001, which means that the number of particles inside the respirator should be 4-times lower than the outside environment, compared to the $\sim 2$ fold decrease that was observed. This can be explained by the fact that the dust respirators were not designed to deal with exposure to UFPs. To test this hypothesis, the data was examined further to determine the effect of the dust respirator on the removal of particles in various size ranges. As anticipated, the removal factor for particles in the UFP size range was only 1.78 compared with 3.10 for particles in the $100-560 \mathrm{~nm}$ size range. The removal factor may increase further (approaching 4) with the increase in particle size over $560 \mathrm{~nm}$, for which these masks are originally designed. Given the scope of this work, that is to understand the UFP protection from 
these masks, tests were not carried out for larger-sized particles.

These results have important implications in relation to human exposure to airborne particles at concrete recycling sites. For example, a $\sim 2$-fold reduction in PNC when using dust respirators would still mean an exposure to up to $\sim 3$ times higher concentrations close to the source compared with those $\left(3.82 \pm 3.25 \times 10^{4} \mathrm{~cm}^{-3}\right)$ observed in typical European roadside environments (Kumar et al., 2013a). These results clearly indicate the need for designing better dust respirators which can effectively remove particles in the UFP size range.

\section{SYNTHESIS AND FUTURE RESEARCH CHALLENGES}

Size-resolved particles in the 5-560 $\mathrm{nm}$ range were measured using a fast response differential mobility spectrometer (DMS50). The measurements were performed at five different locations within $\sim 15 \mathrm{~m}$ periphery of a simulated concrete recycling source to study their study their emission rates, dispersion, exposure levels and the effectiveness of commonly used dust respirators. This study presented evidence, for the first time, that a significant proportion of the airborne particles produced during concrete recycling activities are in the UFP size range. Re-suspension of existing particles and the mechanical attrition between the surfaces of sample material during the mixing is likely to produce larger-sized particles. Possible reason for the presence of UFP particles could be that the dust clouds were frequently observed at the source during the recycling process - these may have contained tiny size particles, presumably made of cement constituents such as limestone, clay and aggregate (Fennell et al., 2007), that may have detached from the surface of concrete debris during mixing. This is possible because concrete is typically made of cement, aggregates, admixtures and water. Cement acts to bind these components together; $\sim 60 \%$ of which is made of Calcium $(\mathrm{CaO})$ Silicate $\left(\mathrm{SiO}_{2}\right)$ Hydrate
$\left(\mathrm{H}_{2} \mathrm{O}\right)$, also known as $\mathrm{C}-\mathrm{S}-\mathrm{H}$. This forms a nonporous, highly cohesive, complex structure containing $10-50 \mathrm{~nm}$ diameter capillary pores in well hydrated form (Raki et al., 2010). Some experimental studies have found presence of nanocrystals with 1$10 \mathrm{~nm}$ size in a disordered organised manner (Donev et al., 2004; Jennings, 2000). This indicates that the breaking of concrete containing small pores can also produce particles in various size ranges. However, detailed chemical and morphology analysis is needed to reach to a clear consensus.

The UFP concentrations showed a much lower spatial decay rate compared with particles in the 100-300 $\mathrm{nm}$ range. In fact, they required $\sim 62 \%$ more distance to reach $10 \%$ of their initial concentrations, compared with the distances needed by particles in the 100-300 $\mathrm{nm}$ range. This is a concerning finding, given that UFPs have a higher respiratory deposition rate than larger particles and that these could remain airborne in higher quantities at distances further away from the source. Exposure decay profiles mimicked the overall trend for total PNC, showing up to $~ 13$ - and 2times higher exposure compared to background PNCs close to and $\sim 15 \mathrm{~m}$ away from the source, respectively. In general, exposure at operational sites is usually controlled by the use of dust respirators. Our results showed that the respirators were only able to reduce total PNC by a factor of $\sim 2$, compared to the classified protection factor of $\sim 4$. In fact, the respirators were found to be less effective in removing UFPs, with a removal factor of only $\sim 1.8$, compared with a much higher removal factor (3.1) for particles in the 100-560 nm size range. These findings have important implications for the C\&D industry, particularly in terms of current health and safety guidelines, as well as environmental regulations worldwide, none of which currently include any specific control measures to protect against UFP exposure for on-site workers, passers-by and those living in close proximity to such sites. Moreover, the current exposure control 
measures used are inefficient at protecting against UFP exposure, primarily because they are not designed for this purpose.

It is recommended that future studies are broadened by conducting detailed physicochemical characterisation and repeating the experiments under varying meteorological conditions around operational sites. Knowledge on the physicochemical characteristics of these particles would serve to explain particle formation mechanisms, and further investigations into the dispersion of UFPs will help to accurately estimate exposure around such sources. Together, these findings could assist in developing efficient risk assessment and management strategies for use in the C\&D industry.

\section{ASSOCIATED CONTENT} S4 and Table S1.

Supporting Information Figures S1-

\section{ACKNOWLEDGEMENTS}

The authors thank Fraser Paris, Dimitrios Mitsis, Farhad Azarmi, Mike Mulheron, Paul Fennell, Juan Sagaseta, Nigel Mobbs, and Rachael Appleby for useful discussions and their contributions in relation to the experimental preparation and data collection for this study.

\section{REFERENCES}

Carpentieri, M., Kumar, P., 2011. Ground-fixed and on-board measurements of nanoparticles in the wake of a moving vehicle. Atmos. Environ. $45,5837-5852$.

Charron, A., Harrison, R.M., 2003. Primary particle formation from vehicle emissions during exhaust dilution in the road side atmosphere. Atmos. Environ. 37, 4109-4119.

Dall'Osto, M., Thorpe, A., Beddows, D.C.S., Harrison, R.M., Barlow, J.F., Dunbar, T., Williams, P.I., Coe, H., 2011. Remarkable dynamics of nanoparticles in the urban atmosphere. Atmospheric Chemistry and Physics 11, 6623-6637.

Donev, A., Cisse, I., Sachs, D., Variano, E.A., Stillinger, F.H., Connelly, R., Torquato, S., Chaikin, P.M., 2004. Improving the Density of
Jammed Disordered Packings Using Ellipsoids. Science 303, 990-993.

EU, 2008. Commission Regulation (EC) No 692/2008. Official Journal of the European Union, pp 136.

Fennell, P.S., Pacciani, R., Dennis, J.S., Davidson, J.F., Hayhurst, A.N., 2007. The effects of repeated cycles of calcination and carbonation on a variety of different limestones, as measured in a hot fluidized bed of sand. Energy \& Fuels 21, 2072-2081.

Fujitani, Y., Kumar, P., Tamura, K., Fushimi, A., Hasegawa, S., Takahashi, K., Tanabe, K., Kobayashi, S., Hirano, S., 2012. Seasonal differences of the atmospheric particle size distribution in a metropolitan area in Japan. Sci. Total Environ. 437, 339-347.

Heal, M.R., Kumar, P., Harrison, R.M., 2012. Particles, air quality, policy and health. Chem. Soc. Rev. 41, 6606-6630.

HEI, 2013. HEI Review Panel on Ultrafine Particles. Understanding the health effects of ambient ultrafine particles HEI Perspectives 3. Health Effects Institute, Boston, MA, pp. 122. http://pubs.healtheffects.org/getfile.php?u=893 (accessed 12 August 2013).

Hinds, W.C., 1999. Aerosol technology: Properties, behaviour and measurement of airborne particles. John Wiley \& Sons, UK, pp. 483.

Holman, C., Barrowcliffe, R., Birkenshaw, D., Dalton, H., Gray, G., Harker, G., Brett, P., Laxen, D., Marner, B., Marsh, D., Prismall, F., Pullen, J., Stoaling, M., Storey, C., Vining, L., 2014. IAQM Guidanceon the assessment of dust from demolition and construction, Institute of Air Quality Management, London. www.iaqm/wpcontent/uploads/guidance/dust_as sessment.pdf. (accessed 11 March 2014)

Holmes, N.S., Morawska, L., 2006. A review of dispersion modelling and its application to the dispersion of particles: An overview of different dispersion models available. Atmos. Environ. 40, 5902-5928.

ICRP, 1994. ICRP Publication 66: Human respiratory tract model for radiological protection A Report of a task group of the International Commission on Radiological Protection, 1-482. 
Janhall, S., Andreae, M.O., Poschl, U., 2010. Biomass burning aerosol emissions from vegetation fires: particle number and mass emission factors and size distributions. Atmospheric Chemistry and Physics 10, 14271439.

Jennings, H.M., 2000. A model for the microstructure of calcium silicate hydrate in cement paste. Cem. Concr. Res. 30, 101-116.

Jones, A.M., Harrison, R.M., Barratt, B., Fuller, G., 2012. A large reduction in airborne particle number concentrations at the time of the introduction of "sulphur free" diesel and the London Low Emission Zone. Atmos. Environ. $50,129-138$.

Jonsson, Å.M., Westerlund, J., Hallquist, M., 2011. Size-resolved particle emission factors for individual ships. Geophysical Research Letters 38, L13809, doi:13810.11029/12011GL047672.

Joodatnia, P., Kumar, P., Robins, A., 2013a. The behaviour of traffic produced nanoparticles in a car cabin and resulting exposure rates. Atmos. Environ. 65, 40-51.

Joodatnia, P., Kumar, P., Robins, A., 2013b. Fast response sequential measurements and modelling of nanoparticles inside and outside a car cabin. Atmos. Environ. 71, 364-375.

Keogh, D.U., Ferreira, L., Morawska, L., 2009. Development of a particle number and particle mass vehicle emissions inventory for an urban fleet. Environmental Modelling \& Software 24, 1323-1331.

Kuhlbusch, T., Asbach, C., Fissan, H., Gohler, D., Stintz, M., 2011. Nanoparticle exposure at nanotechnology workplaces: A review. Particle and Fibre Toxicology 8, 22.

Kulmala, M., Kontkanen, J., Junninen, H., Lehtipalo, K., Manninen, H.E., Nieminen, T., Petäjä, T., Sipilä, M., Schobesberger, S., Rantala, P., Franchin, A., Jokinen, T., Järvinen, E., Äijälä, M., Kangasluoma, J., Hakala, J., Aalto, P.P., Paasonen, P., Mikkilä, J., Vanhanen, J., Aalto, J., Hakola, H., Makkonen, U., Ruuskanen, T., Mauldin, R.L., Duplissy, J., Vehkamäki, H., Bäck, J., Kortelainen, A., Riipinen, I., Kurtén, T., Johnston, M.V., Smith, J.N., Ehn, M., Mentel, T.F., Lehtinen, K.E.J., Laaksonen, A., Kerminen, V.-M., Worsnop, D.R., 2013. Direct observations of atmospheric aerosol nucleation. Science 339, 943-946.
Kumar, P., Fennell, P., Britter, R., 2008a. Effect of wind direction and speed on the dispersion of nucleation and accumulation mode particles in an urban street canyon. Sci. Total Environ. 402, 82-94.

Kumar, P., Fennell, P., Langley, D., Britter, R., 2008b. Pseudo-simultaneous measurements for the vertical variation of coarse, fine and ultra fine particles in an urban street canyon. Atmos. Environ. 42, 4304-4319.

Kumar, P., Fennell, P., Symonds, J., Britter, R., 2008c. Treatment of losses of ultrafine aerosol particles in long sampling tubes during ambient measurements. Atmos. Environ. 42, 8819-8826.

Kumar, P., Robins, A., ApSimon, H., 2010a. Nanoparticle emissions from biofuelled vehicles - their characteristics and impact on the numberbased regulation of atmospheric particles. Atmospheric Science Letters 11, 327-331.

Kumar, P., Robins, A., Vardoulakis, S., Britter, R., 2010b. A review of the characteristics of nanoparticles in the urban atmosphere and the prospects for developing regulatory controls. Atmos. Environ. 44, 5035-5052.

Kumar, P., Gurjar, B.R., Nagpure, A., Harrison, R.M., 2011a. Preliminary estimates of nanoparticle number emissions from road vehicles in megacity Delhi and associated health impacts. Environ. Sci. Technol. 45, 5514-5521.

Kumar, P., Robins, A., Vardoulakis, S., Quincey, P., 2011b. Technical challenges in tackling regulatory concerns for urban atmospheric nanoparticles. Particuology 9, 566571.

Kumar, P., Azarmi, F., Mulheron, M., 2012a. Enlightening and noxious shades of nanotechnology application in concrete. In: Nanotechnology: Volume 9 Civil / Construction Engineering. (Studium Press LLC, USA; Govil, J.N. Eds.). ISBN: 1-62699-009-3). pp. 255-287.

Kumar, P., Mulheron, M., Fisher, B., Harrison, R.M., 2012b. New Directions: Airborne ultrafine particle dust from building activities - a source in need of quantification. Atmos. Environ. 56, 262-264.

Kumar, P., Mulheron, M., Som, C., 2012c. Release of ultrafine particles from three simulated building processes. J. Nanopart. Res. 14, 771, DOI 10.1007/s11051-012-0771-2. [http://dx.doi.org/10.1007/s11051-012-0771-2] 
Kumar, P., Morawska, L., Harrison, R., $2013 a$. Nanoparticles in European Cities and Associated Health Impacts, in: Viana, M. (Ed.), Urban Air Quality in Europe. Springer Berlin Heidelberg, Volume 26, pp. 339-365. [http://dx.doi.org/10.1007/698_2012_161]

Kumar, P., Pirjola, L., Ketzel, M., Harrison, R.M., 2013b. Nanoparticle emissions from 11 non-vehicle exhaust sources - a review. Atmos. Environ. 67, 252-277.

Kumar, P., Morawska, L., Birmili, W., Paasonen, P., Hu, M., Kulmala, M., Harrison, R.M., Norford, L., Britter, R., 2014. Ultrafine particles in cities. Environment International 66, 1-10.

Li, X., 2008. Recycling and reuse of waste concrete in China: Part I. Material behaviour of recycled aggregate concrete. Resources, Conservation and Recycling 53, 36-44.

Monier, V., Hestin, M., Trarieux, M., Mimid, S., Domröse, L., Van Acoleyen, M., Hjerp, P., Mudgal, S., 2011. Study on the management of construction and demolition waste in the EU. Contract 07.0307/2009/540863/SER/G2, Final report for the European Commission (DG Environment) http://www.eusmr.eu/cdw/docs/BIO_Construction\%20and\%2 0Demolition\%20Waste_Final\%20report_09022 011.pdf (accessed 12 November 2013).

Morawska, L., He, C., Johnson, G., Jayaratne, R., Salthammer, T., Wang, H., Uhde, E., Bostrom, T., Modini, R., Ayoko, G., McGarry, P., Wensing, M., 2009. An investigation into the characteristics and formation mechanisms of particles originating from the operation of laser printers. Environ. Sci. Technol. 43, 1015-1022.

Morawska, L., Ristovski, Z., Jayaratne, E.R., Keogh, D.U., Ling, X., 2008. Ambient nano and ultrafine particles from motor vehicle emissions: Characteristics, ambient processing and implications on human exposure. Atmos. Environ. 42, 8113-8138.

Paasonen, P., Visshedjik, A., Kupiainen, K., Klimont, Z., van der Gon, H.D., Kulmala, M., Amann, M., 2013. Aerosol particle number emissions and size distributions: Implementation in the GAINS model and initial results. IIASA Interim Report.

Pirjola, L., Paasonen, P., Pfeiffer, D., Hussein, T., Hämeri, K., Koskentalo, T., Virtanen, A., Rönkkö, T., Keskinen, J., Pakkanen, T.A.,
Hillamo, R.E., 2006. Dispersion of particles and trace gases nearby a city highway: mobile laboratory measurements in Finland. Atmos. Environ. 40, 867-879.

Raki, L., Beaudoin, J., Alizadeh, R., Makar, J., Sato, T., 2010. Cement and Concrete Nanoscience and Nanotechnology. Materials 3, 918-942.

Sanchez, F., Sobolev, K., 2010. Nanotechnology in concrete - A review. Construction and Building Materials 24, 2060-2071.

Schröder, F., Petzold, A., Kärcher, B., 1998. Ultrafine particulate jet aircraft emissions depending on fuel sulfur content and contrail processing. J. Aerosol Sci 29, S561-S562.

Shi, J., Xu, Y., 2006. Estimation and forecasting of concrete debris amount in China. Resources, Conservation and Recycling 49, 147-158.

UNECE, 2013. United Nations Statistics commision of Europe. Statistical Data http://w3.unece.org/pxweb/Dialog/Saveshow.as p?lang=1 (accessed 29 August 2013).

Vardoulakis, S., Fisher, B.R.A., Pericleous, K., Gonzalez-Flesca, N., 2003. Modelling air quality in street canyons: a review. Atmos. Environ. 37, 155-182.

WBCSD, 2009. World Business Council for Sustainable Development: The Cement Sustainability Initiative. ISBN: 978-3-94038850-6, pp. 1-8.

WHO., 2013. Review of evidence on health aspects of air pollution - REVIHAAP. World Health Organisation, Regional Office for Europe pp. 33, http://www.euro.who.int/_data/assets/pdf_file/ 0020/182432/e96762-final.pdf (accessed 09 Septermber 2013).

Zhu, Y., Hinds, W.C., Kim, S., Shen, S., Sioutas, C., 2002. Study of ultrafine particles near a major highway with heavy-duty diesel traffic. Atmos. Environ. 36, 4323-4335. 


\section{Supporting Information (SI)}

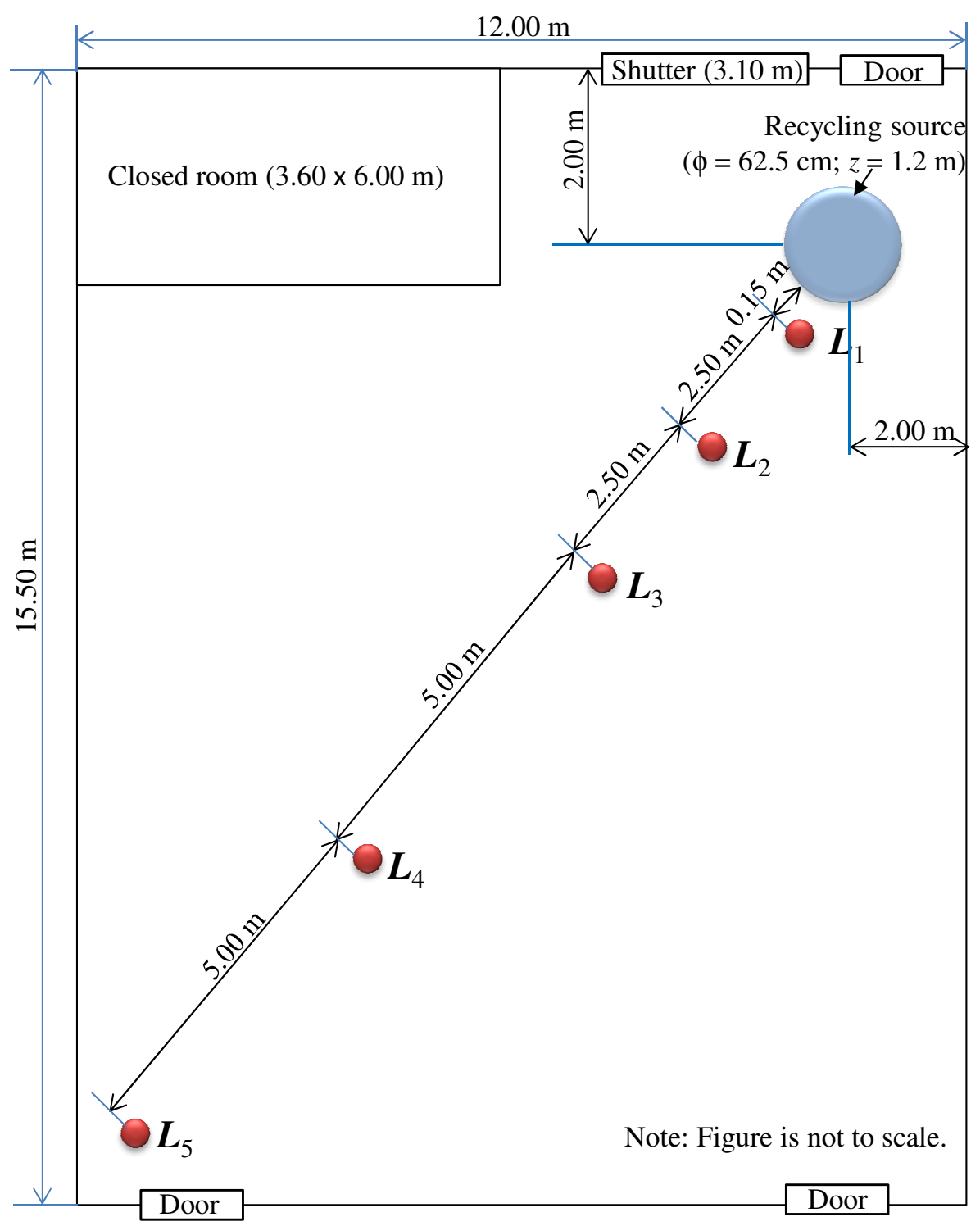

Figure S1. Schematic representation of the sampling locations in Surrey Construction Material laboratory. All the doors and shutter were closed during the recycling period, but these were left open during the no-activity period to attain a steady background for the next set of measurements. The laboratory has mechanically operated exhaust fans but these were switched-off during the measurements and the ventilation was governed naturally by the ventilators on the right hand side wall, which were partially opened to allow air from outside. The ambient wind speed during the measurements was fairly low $(0.8-1.8 \mathrm{~m} / \mathrm{s})$, providing limiting ventilation and nearly stable conditions inside the lab. 


\section{S1. Estimation of particle emission strengths}

Emission strength is estimated in the following three formats: (i) emitted total particle numbers per unit $\left(\# \mathrm{~s}^{-1}\right)$, (ii) emitted total particle numbers per unit time per unit mass of concrete recycled $\left(\# \mathrm{~kg}^{-1} \mathrm{~s}^{-1}\right)$, and (iii) emitted total particle numbers per unit mass of concrete recycled (\# $\mathrm{kg}^{-1}$ ). For all the cases, concentrations per unit time are estimated by using the expression, $C_{\mathrm{L} 1} / t$, where $C_{\mathrm{L} 1}$ is the sum of the concentrations $\left(\# \mathrm{~cm}^{-3}\right.$ ) measured at $L_{1}$ (nearest sampling point around the source) during the recycling activity period $(t ; \mathrm{s})$. For the (i), $C_{\mathrm{L} 1} / t\left(\# \mathrm{~cm}^{-3}\right)$ is multiplied by the volumetric flow rate $\left(6.5\right.$ lit $\left.\mathrm{min}^{-1}=108.33 \mathrm{~cm}^{3} \mathrm{~s}^{-1}\right)$ of the DMS50 at which the particle samples were drawn from the source to calculate emission rates per second $\left(\# \mathrm{~s}^{-1}\right)$. For the (ii), values obtained from (i) are divided by the mass $(m ;=30 \mathrm{~kg})$ of concrete recycled in order to find emission rates per unit time per unit mass $\left(\# \mathrm{~kg}^{-1} \mathrm{~s}^{-1}\right.$ ). For the (iii), values obtained from (ii) are multiplied by the typical time of total recycling activity in order to obtain the emission rates per unit mass of concrete recycled $\left(\# \mathrm{~kg}^{-1}\right)$. The typical time of waste concrete recycling can vary from a few second to 10's of seconds, depending on the type of crushers used in various capacity of the plants ranging from 6 to over $20 \mathrm{~m}^{3} \mathrm{~h}^{-1}$, which is equivalent to $14,400-48,000 \mathrm{~kg} \mathrm{~h}^{-1}$ based on the bulk density of recycled concrete as $2400 \mathrm{~kg} \mathrm{~m}^{-3}$. If the plant configurations are known correctly, the he emission rates in $\# \mathrm{~kg}^{-1}$ could be estimated based on the emission rates estimated as part of (ii). We have therefore used the (i) and (ii) for our emission calculations.

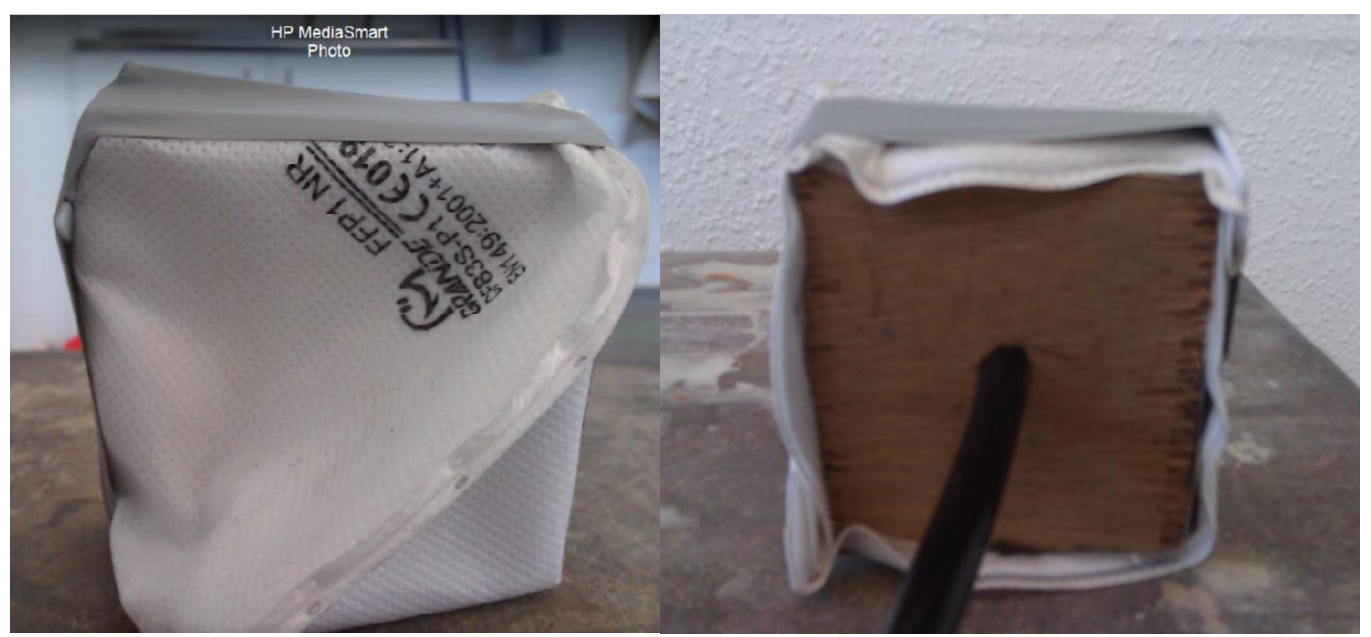

Figure S2. Arrangement of dust respirators for particle measurements. 

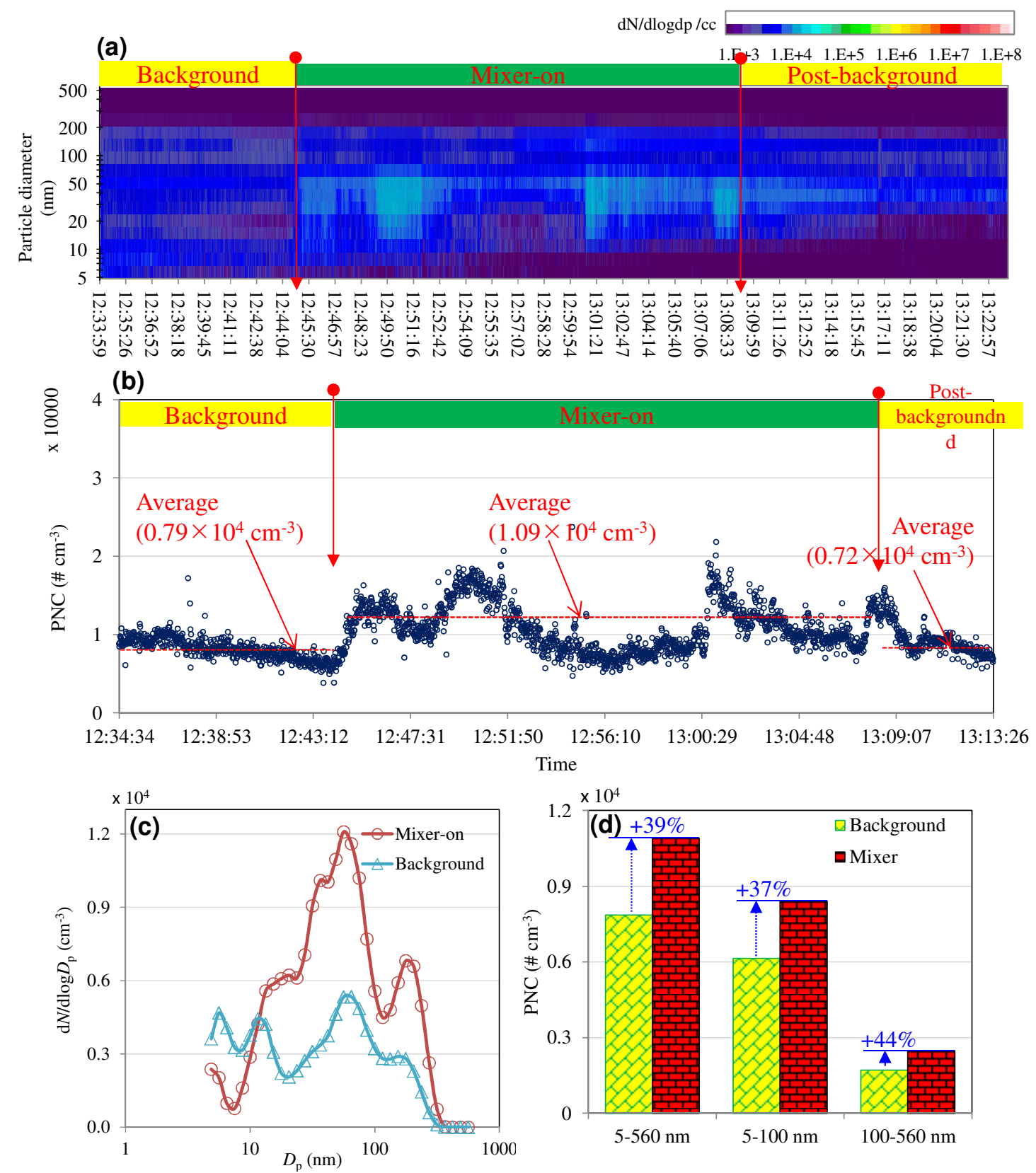

Figure S3. A separate set of measurements for defining the mixer contributions, showing: (a) contour plot of size-resolved particles in the 5-560 nm size range, (b) corresponding PNCs, (c) average PNDs, and (d) fraction of PNCs in various size ranges - the mixer component includes background and the percentage value mentioned are the contribution from the mixer. 


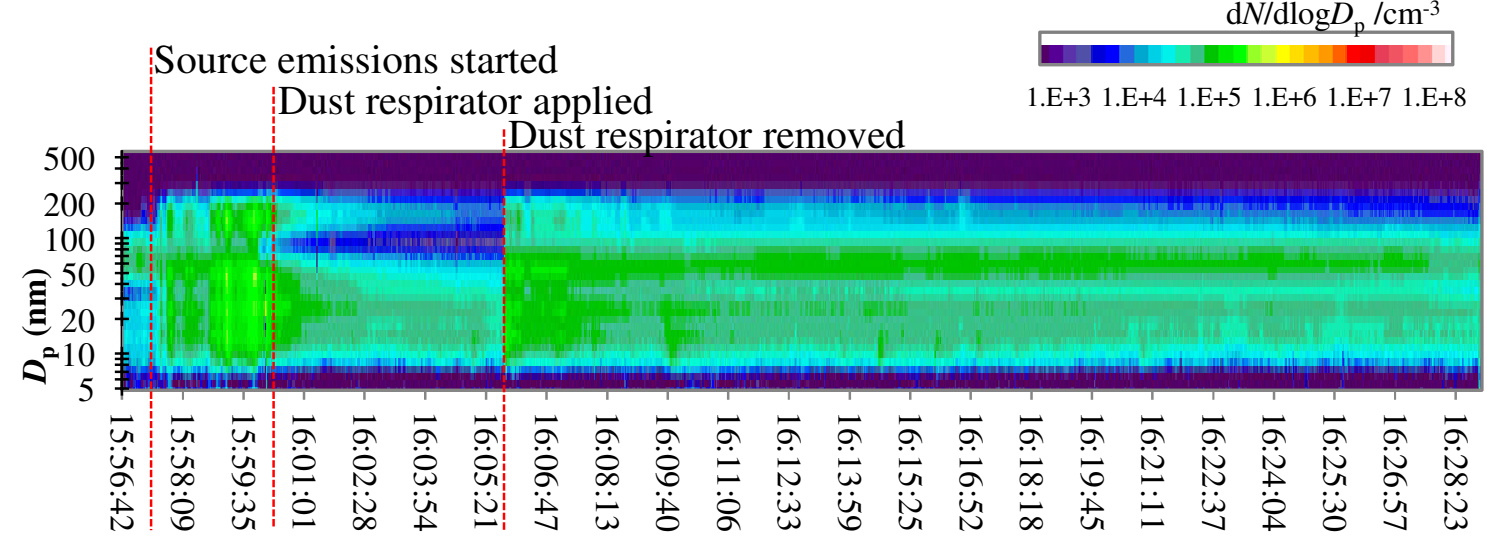

Figure S4. Contour plots of particle number distributions with and without the dust respirator.

Table S1. Summary of PNCs $\left(\# \mathrm{~cm}^{-3}\right.$ ) observed during separate set of experiments to analyse contribution from mixer.

\begin{tabular}{llll}
\hline & $5-560 \mathrm{~nm}$ & $5-100 \mathrm{~nm}$ & $100-560 \mathrm{~nm}$ \\
\hline Background & $0.79 \times 10^{4}$ & $0.61 \times 10^{4}$ & $1.72 \times 10^{3}$ \\
\hline Mixer (+ background) & $1.09 \times 10^{4}$ & $0.84 \times 10^{4}$ & $2.48 \times 10^{3}$ \\
\hline Mixer only (net) & $0.31 \times 10^{4}$ & $0.23 \times 10^{4}$ & $0.76 \times 10^{3}$ \\
\hline Increase (\%) & 38.70 & 37.11 & 44.34 \\
\hline
\end{tabular}

